\title{
ANALYSIS OF THE ROLE OF THE LATVIAN NATURAL GAS NETWORK FOR THE USE OF FUTURE ENERGY SYSTEMS: HYDROGEN FROM RES
}

\author{
J. Kleperis*1, D. Boss ${ }^{1}$, A. Mezulis ${ }^{1}$, L. Zemite², \\ P. Lesnicenoks ${ }^{1,3}$, A. Knoks ${ }^{1}$, I. Dimanta ${ }^{1,4}$ \\ ${ }^{1}$ Institute of Solid State Physics of University of Latvia, \\ 8 Kengaraga Str., Riga, LV-1063, LATVIA \\ 2 Riga Technical University, Institute of Energetics, \\ 12/1 Azenes Str., Riga, LV-1048, LATVIA \\ ${ }^{3}$ Riga Technical University, \\ Faculty of Materials Science and Applied Chemistry, \\ 3/7 P.Valdena Str., Riga, LV-1048, LATVIA \\ ${ }^{4}$ Faculty of Biology, University of Latvia, \\ 1 Jelgavas Str., Riga, LV-1004, LATVIA \\ *e-mail: Janis.kleperis@cfi.lu.Iv
}

As EU is steadily moving in the direction of emission reduction, each country must develop plans to decarbonise the transport and energy sectors. In Latvia, transport sector is one of the biggest emission sources. The heating applications come next. Both require carbon containing fuels and a transfer to carbon neutral fuel is necessary; therefore, hydrogen may be the answer to achieve the overall EU targets. As Latvia has renewable energy sources, some production, storage and use of hydrogen are possible. Currently clear guidelines for Latvia have been investigated. The existing natural gas network may be used for two tasks: largescale hydrogen transportation and decarbonisation of natural gas network. To open the natural gas networks for hydrogen, the first evaluations are made and a possible scenario for hydrogen implementation in network supplying consumers in the household sector is analysed to evaluate decarbonisation with an overarching goal of carbon neutrality.

Keywords: Decarbonisation, HCNG blending, hydrogen, natural gas, NG networks. 
The existing EU natural gas (NG) network provides large capacity to integrate renewable (bio-methane, hydrogen) and low-carbon gases (synthetic methane, hydrogen/compressed natural gas (HCNG) blends); therefore, transformation of the gas network for hydrogen applications may provide a cost-efficient solution [1].

Today, hydrogen contributes less than $2 \%$ of Europe's energy consumption [2] and is almost exclusively produced from fossil fuels and used in industry. Nevertheless, hydrogen has a significant role to play in emission reduction in hard-to-decarbonise sectors, in particular, as a fuel in certain transport applications and as a fuel or feedstock in certain industrial processes (steel, refining or chemical industries - including the production of 'green fertilisers' for agriculture) [1], [2]. Carbon dioxide in reaction with hydrogen can also be further processed into synthetic fuels, such as synthetic kerosene in aviation. In addition, hydrogen brings other environmental cobenefits when used as fuel, such as the lack of air pollutant emissions.

The priority for the EU is to develop hydrogen production from renewable electricity, which is the cleanest solution [2]. In other words, the aim is to develop green hydrogen production in the EU. However, in transitional phase other forms of lowcarbon hydrogen, for example, $\mathrm{HCNG}$, are needed to replace the existing NG and kickstart an economy of scale.

The gas networks may use hydrogen blend of 5-20\% by volume and be tolerated by most systems without the need for major infrastructure upgrades or end-use appliance retrofits or replacements [3]. The trans- mission of existing natural gas networks to hydrogen network is one of the main aspects to achieve the hydrogen availability and in the meantime large-scale transportation. The promotion of hydrogen network as the EU backbone is gaining momentum in Central Europe, and the development of a hydrogen backbone activity is ongoing [4].

To decarbonise the NG grids, the threshold of hydrogen allowance in the existing grid systems must be increased. Considering that the assessment of hydrogen injection in the Latvian gas grid will be developed in 2021, the first initial analysis can already be made, and experience gained from other countries can be replicable. To create a consistent and long-lasting plan, the current energy sector players must participate in the development of this strategy, as actors in the field have command of currently used facilities and technologies.

Analysis of hydrogen introduction into the Latvian energy sector is performed in this article. The blending of green hydrogen produced by renewable sources in the NG network at a limited percentage is a key element to enable hydrogen production in a preliminary and transitional phase (2020-2030). The present article deals with the evaluation of (i) the potential of green hydrogen blending at low percentage (up to $20 \%$ ) in the Latvian gas network and (ii) the maximum power-to-gas $(\mathrm{P} 2 \mathrm{G})$ capacity compatible with low percentage blending. The paper aims to provide preliminary assessment of the green hydrogen blending potential into the Latvian natural gas network as a tool for policy makers, grid and network managers, as well as energy planners. 


\subsection{The Main Aspects from Experience of Other EU Countries}

Preliminary assessments and tests in the EU countries [3], [5]-[7] show that it is urgent to evaluate at the same time (i) the potential of green hydrogen blending at low percentage (up to $10 \%$ ) and (ii) the maximum of available $\mathrm{P} 2 \mathrm{H}$ capacity compatible with low percentage blending. If the first estimates purely theoretically calculate the maximum possible amounts of hydrogen gas that can be filled into the existing national NG networks at low impurity concentrations [5], [6], then real experiments are performed in separate network sections, e.g., in Germany and Denmark with "windgas", France (Dunkerque), the UK (Keele, Leeds), Italy (Salerno).

The work carried out by French operators [5] shows that it is possible to integrate a significant volume of hydrogen into the gas mix by 2050 , with limited infrastructure adaptation costs. In the short term, hydrogen can be blended in the most networks up to $6 \%$ (volume) without any additional installations on the customer's premises. The first task will be to determine suitable areas for injection project owners. These areas will be extended gradually to align with the results of R\&D and equipment replacement actions. By 2030, operators recommend setting a target capacity for integrating hydrogen/NG blends into the networks of $10 \%$ and $20 \%$ thereafter. The goal is to anticipate the need to adapt equipment for downstream users at a distribution level. The work carried out for this report shows additional areas of relevance for the three injection routes by 2050: blending, methanation and $100 \%$ hydrogen clusters.

In Italy, two different networks are operated [6]: the transportation and the distribution networks. More than $90 \%$ of natu- ral gas is imported from foreign countries through 7 points. The Italian distribution system is responsible for natural gas supply to final customers. Almost $30 \mathrm{GSm}^{3}$ of natural gas, equivalent to almost $300 \mathrm{TWh}$, is annually supplied by more than 200 Distribution System Operators (DSO) to more than 23 million final Italian customers. More than 500 connection points between distribution and transmission networks are present and each of them would become a hydrogen blending point. A very complex coordination among DSOs would be therefore required to not exceed the hydrogen concentration threshold. Therefore, hydrogen blending is assumed only in the Italian transmission gas system, which is considered an option for location of $\mathrm{P} 2 \mathrm{H}$ plants. Even if the Italian regulation allows for hydrogen concentration for blending only up to $1.0 \%$ [6], as defined for biomethane injection, experimental activities have been already performed in existing networks: $5 \%$ blending has been already tested in a small closed network near the southern city of Salerno (see references in [6]). Up to 8100 ton/year of green hydrogen blending, i.e., $715,000 \mathrm{Sm}^{3} /$ year can be injected right now in the existing Italian NG network with a proper location and sizing of $\mathrm{P} 2 \mathrm{H}$ plants with an installed capacity of about $78 \mathrm{MW}$ of electrolyzers and about 488 MEUR of investment.

As mentioned prior, also in UK ativities to evaluate hydrogen blending into NG grid are ongoing. HyDeploy [7] is H2020 project in the UK. ITM Power (the energy storage and clean fuel company) has announced that the UK's first pilot project HyDeploy to inject zero carbon hydrogen into a gas network to heat homes and businesses is now 
fully operational. In 2018, the HSE granted the HyDeploy consortium an exemption to the current limit of $0.1 \%$ hydrogen in the UK gas network. The exemption to $20 \%$ hydrogen for the project at Keele was awarded after the project gathered extensive evidence, which was scrutinised by the HSE, to demonstrate the hydrogen blend would be 'as safe as natural gas'. The UK's first live pilot to inject zero carbon hydrogen into the gas network to heat homes

\subsection{The Latvian Gas Grid}

The Latvian emission reduction strategy states that the main factor for $\mathrm{GHG}$ emission reduction is to increase the overall energy efficiency and to substitute fossil energy resources with bio-gas or other renewables [8].

The modern NG transmission system, which is part of the Conexus Baltic JSC company structure, is $1188 \mathrm{~km}$ long and it directly connects the Latvian natural gas market with Lithuania, Estonia and Russia [9]. The Latvian transmission system is not directly connected with the European gas network. Since the liquid natural gas terminal is in operation in Lithuania, there is an option to use not only the natural gas from Russia but also from other countries.

The oldest operating tubes were manufactured in 1967; thus, the renewal of existing infrastructure is ongoing. The Latvian transmission NG grid is connected with transmission systems of neighbouring countries - Estonia, Russia and Lithuania. The cross-country connections with Estonia allow securing the natural gas flow only in one direction. The connections with Lithuania and Russia ensure the flow in both directions [10].

Within the heating period, the main source of natural gas is the Incukalns underground gas storage (UGS) facility. It is one of the most significant infrastructures of the and businesses is now fully operational. The HyDeploy demonstration is injecting up to $20 \%$ (by volume) of hydrogen into Keele University's existing NG network, feeding 100 homes and 30 faculty buildings. The $20 \%$ hydrogen blend is the highest in Europe. If a $20 \%$ hydrogen blend were rolled out across the UK, it could save around 6 million tonnes of carbon dioxide emissions every year, the equivalent of taking 2.5 million cars off the road [7].

Latvian NG grid network. Incukalna UGS facility is the only functional storage in the Baltic countries with an overall capacity of 4.47 bil. $\mathrm{m}^{3}$ of natural gas [11]. Incukalns UGS is in operation because in the depths of the Latvian soil there is a layer of porous sandstone, which has good storage properties and which is coated with gas-tight rock layers. These geological structures are also placed at the optimal depth level of 700-800 meters, allowing for safe and costefficient storage of gas [9], [12]. The main technical gap with HCNG blends into Incukalna UGS is the identification of potential chemical reactions in underground water. It could lead to microorganisms consuming dissolved hydrogen, to the production of hydrogen sulphide, and to the development of biofilms near wells (risk of corrosion) [1]. Specific research of Incukalns UGS must be conducted where material compatibility with gaseous hydrogen is tested and evaluated. Analogical evaluation is ongoing within the RINGS project that is performed by the University of Pau and Pays de l'Adour (UPPA) and Teréga (France). Within the project, laboratory experiments of reproduction of reservoir conditions using samples of rock, micro-organisms aquifer water and variable gas composition will be done [13]. The interim results will be available in 2021 and could be useful as 
a starting point for Incukalns UGS evaluation [14].

What tactics to use when choosing hydrogen entry points in the Latvian natural gas network? This issue cannot be solved in this article. The assessment of potential injection locations must be done in close cooperation with the network operators (CONEXUS, GASO). In order not to affect the supply of clean natural gas to Estonia and Lithuania from the Incukalns UGS facility, experiments with the storage facility and distribution branches to Estonia and Lithuania should not be exercised in the original hydrogen blending plan. This is due to the fact that hydrogen impact on Incukalns UGS materials is not known and should be tested and evaluated prior larger pilots or activities. Thus, for the first evaluations smaller branches should be used, such as Daugavpils, Liepaja.

\subsection{Pipelines and Characterisation of $\mathrm{H}_{2} / \mathrm{NG}$ Blends}

If hydrogen mixture is increased in the natural gas systems, the first assessment of existing pipeline system must be made. Gaseous hydrogen can be stored and transported in pipelines. Evaluations to use the existing natural gas pipeline network are ongoing and the first aspects are already outlined, such as the usage of polymer pipes or specific coating of existing pipelines.

The need for modification varies from the intended concentration of hydrogen in the pipelines. Pipelines themselves need little modification, and new stretches of dedicated hydrogen pipeline do not differ a lot from NG pipelines either. However, depending on the capacity at which the pipeline is operated, major modifications on the compressor stations may be needed. Hydrogen has lower energy density per volume than natural gas: at the same pressure, a cubic meter of hydrogen only contains $1 / 3$ of the energy density of a cubic meter of natural gas. However, this does not mean that three times as many pipelines are required to transport the same amount of energy.
The volume flow of hydrogen can be higher than for natural gas, bringing the maximum energy capacity of hydrogen pipeline to a value of up to $80 \%$ of the energy capacity it has when transporting natural gas [4].

As one of the solutions to transform the gas network pipes suitable for hydrogen transportation is to use an inner coating. The inner coating would chemically protect the steel layer and reduce the hydrogen diffusion into the metal. This aspect might allow increasing the overall pressure in the tubes. Initial hydrogen conversion projects in Germany and the Netherlands have shown that existing pipelines in those regions do not require internal coating; studies in France show that re-coating can be a viable part of the optimisation solution by enabling pipes to be operated at pressures closer to the pressure of natural gas [4].

In order to inject the green hydrogen in NG network, it must be produced. Currently, different options for green hydrogen production are available and suitable for the Latvian situation.

\section{RESULTS AND DISCUSSION}

\subsection{Evaluation of Available RES and Hydrogen from them}

In 2018, Latvia had the third highest share of RES (40.3\%) in the energy con- sumption in the European Union (EU) after Sweden (54.6\%) and Finland (41.2\%), 
while the EU average indicator constituted $18.0 \%$ [15]. In order to maintain its place, the Latvian operator directs all the energy produced by RES to its own consumption, and only surplus energy that is left at any given time can be allocated to hydrogen production. Table 1 provides information on electricity produced from renewable energy resources in Latvia in 2018 [5], [19] and the estimated amount of hydrogen produced.

Table 1. Electricity Produced from Renewable Energy Resources in Latvia in 2018 (GWh) and the Estimated Amount of Hydrogen (Tonnes) Produced [15], [19]

\begin{tabular}{|l|c|c|}
\hline Resources & $\begin{array}{c}\text { Electricity produced } \\
\text { GWh/annually }\end{array}$ & $\begin{array}{c}\text { Hydrogen produced, } \\
\text { tonnes/annually }\end{array}$ \\
\hline Hydroelectric power plants together & 2431 & 44200 \\
\hline Average annual surplus from spring floods & 280 & 5090 \\
\hline Wind power plants & 122 & 2218 \\
\hline Biomass cogeneration plants and power plants & 570 & 10364 \\
\hline Total biogas cogeneration plants & 374 & 6800 \\
\hline Solar microgenerators and power plants & 1 & 18 \\
\hline
\end{tabular}

To ensure constant hydrogen pressure within the selected gas grid system at the same time sustaining high fraction of renewable hydrogen, it should be produced locally in Latvia from surplus electricity generated in RES. Even though, there are many possible hydrogen production technological solutions, at this moment for Latvia the best option is conventional alkali-based electrolysis (PEM electrolysers for largescale applications are developing quickly [4]). That will require certain amount of electricity $\left(55 \mathrm{kWh} / \mathrm{kg} \mathrm{H}_{2}\right.$ [4]) and there are four main renewable energy sources that are meaningful to use under current conditions: hydro, wind, solar and biogas energy. Small- to medium-scale plants can participate and create a buffer for a steady hydrogen flow in the gas grid.

Hydroelectric power plants. Latvia has many potential places for small-scale hydro power plants that could utilize seasonal floods for hydrogen production creating $\mathrm{H}_{2}$ buffer, but high peak production is expected only 1-2 months a year (March, April). Is it enough for a steady buffer level? The net electricity consumption in Latvia totalled $7410215 \mathrm{MWh}$ in 2018 , local generation covered $87.7 \%$ of national consumption [15]. However, if we look at the volumes of electricity produced and consumed in Latvia in 2018 by month (Fig. 1), it can be observed that in the first four months of the year more electricity is produced than consumed. The reason is the spring floods and a high water level in the largest river of Latvia, the Daugava, on which three of Latvia's largest hydroelectric power plants are located. This amount of surplus electricity changes year by year, and an average value for last 5 years was $280 \mathrm{GWh} /$ /annually $(2020-45,2019-35$, 2018 - 5440, 2017 - 817, 2016 - 242) [15]. About 5090 tonnes of hydrogen can be produced from such amount of electricity (Table 1$)$. In order to assess the capacity of the electrolyser to be installed at the Daugava hydroelectric power plant for processing the remaining electricity into hydrogen, the maximum observed amount of excess electricity per month must be taken. In the reporting period (2016-2020) it was 303 GWh in March 2017, which corresponded to $421 \mathrm{MW}$ of electrolysis equipment (about two times lower if hydrogen compressing, storage and transportation energies are accounted). 


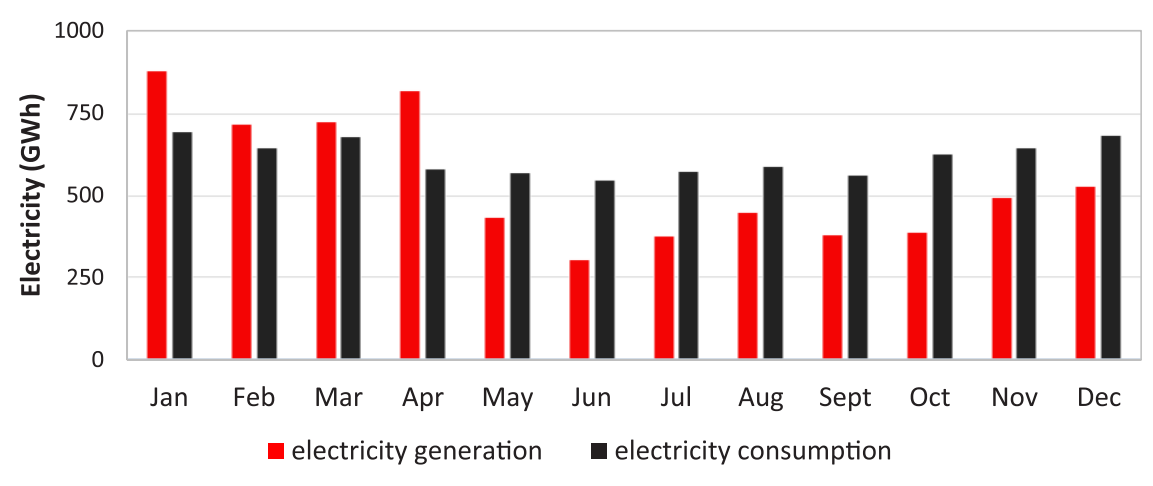

Fig. 1. Total net balance of the Latvian electricity generation \& consumption in 2018 [15].

At present, surplus electricity generated by hydropower plants is sold in neighbouring countries, but there are at least two scenarios for using it as an energy carrier themselves:

1. Reversible power-to-gas process (P2G®G2P) - use surplus electricity to produce hydrogen in the electrolysis process, store hydrogen in compressed form in large cylinders or empty underground gas pipes and convert it back into electricity with powerful fuel cell plants in months when less power is produced in hydroelectric power plants to cover consumption deficits;

2. Simple $P 2 G$ process - use surplus electricity to produce hydrogen in the electrolysis process, store hydrogen in compressed form in cylinders for the gradual injection into the natural gas network with the aim of improving the natural gas combustion process for the end user - to reduce nitrogen oxide and $\mathrm{CO}_{2}$ emissions.

Solar PV plants. Despite assumption, solar energy can be harvested in Latvia throughout the year, as it was clearly shown by Telicko et al. who investigated the type and orientation influence on the production capacity from an experimental set up. They concluded that orientation losses did not exceed $20 \%$ and currently monocrys- talline panels provided more power [16]. This was elaborated empirically by "Saules Darzs" with net capacity of $40 \mathrm{~kW}$ and initially planned production of $58 \mathrm{MWh}$. In the first running year, it produced $45 \mathrm{MWh}$, with average production of $0.477 \mathrm{MWh}$ in winter months and $6.83 \mathrm{MWh}$ in late spring and summer months [17]. As the solar and wind (as well as aforementioned hydro) energy sources are seasonal (in span of days, weeks, months, and years depending on the source), localized hydrogen production and storage systems must be implemented to ensure a steady state hydrogen flow in the gas system. The same conclusion was reached with regard to the evaluation of solar energy use for central heating due to specificity of solar production in Latvia [18].

Wind power plants. Regarding wind energy utilisation in Latvia, firstly, we have to consider availability of this resource. As it has been extensively shown, the highest wind velocities and power are recorded in the western part of Latvia. Winds reach over $7.5 \mathrm{~m} / \mathrm{s}$ along the Baltic Sea coastline. If we consider 2018 and compare the produced electricity from hydro, wind, cogeneration and solar, we see (as shown in Table 1) that solar and wind energy sources are still not optimum for diverting some amount of electricity for production of hydrogen. Thus, new plants should be built in places 
where a potential of electricity generation is hight and the produced hydrogen would be available for injection into a gas grid.

Biogas cogeneration plants. In 2018, there were 59 biogas plants with installed capacity of $63 \mathrm{MW}$ in operation in Latvia, used mostly for the production of electricity - 374 GWh in 2018 [14], [17]. This electricity, at least partly can be used for production of hydrogen to participate in biogas upgrading in biomethane through bio-fermentation of local $\mathrm{CO}_{2}$. Production of biomethane with its subsequent injection into the natural gas grids would be a more cost-effective option in terms of economy and sustainable transformation of the natural gas sector [14].

The distance between the gas networks and the main RES. When considering hydrogen production in Latvia, it is necessary to assess the distance from the local production sites till the gas grid. If the potential hydrogen production facility is located away from the gas grid, the hydrogen is needed to be transported to the injection point.

The main gas grid net stretches throughout Latvia; if we combine possible power sources as wind distribution [20] and available major hydro-powerplants on the map (Fig. 2), we can estimate whether the additional transportation is necessary. It is noteworthy that generally solar production has not major hot spots, as the average solar irradiance can produce $2.72 \mathrm{kWh} / \mathrm{m}^{2}$. day; on the other hand, the maximum amount is $2.92 \mathrm{kWh} / \mathrm{m}^{2}$. day, which overlaps with the wind distribution map. In Fig. 2, we see that the main NG network branch RigaDaugavpils is in very close proximity to larger hydro-power plant Plavinas in the middle of the city of Aizkraukle; therefore, further evaluations should be made in order to assess the potential of direct pipeline connection. The closest point is just beside Plavinas HPP territory - the Gas Regulation Station (GRS) "Aizkraukle" in Jaunberzini, Aizkraukle parish, Aizkraukle district.

As for the wind power, it is not so clear. The main locations of wind farms only partially overlap with Iecava-Liepaja branch. Therefore, if hydrogen is produced from the wind energy in Latvia, the injection in the natural gas grid could be established in Iecava-Liepaja branch. The distance does not exceed $100 \mathrm{~km}$; thus, the most costeffective and efficient solution for power transportation should be evaluated, which is out of the scope of the present study.

The proximity of biogas plants to the NG grids is shown in [14] - the fourteen biogas plants from 59 can relatively easily be connected to grids (five of them are located less than $1 \mathrm{~km}$, nine are located less than $5 \mathrm{~km}$ ) [14].

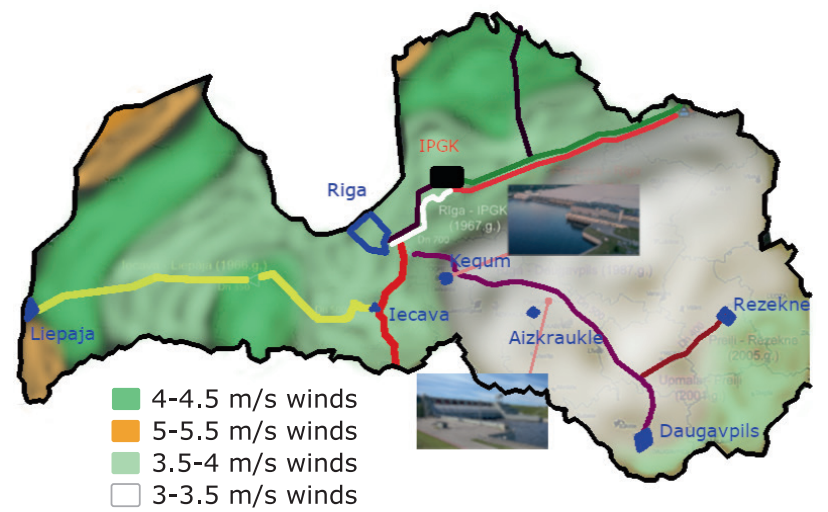

Fig. 2. Wind velocity map overlay and the Latvian gas grid, locations of major cities. 
Evaluation of power to produce hydrogen for blending NG networks. It is possible to calculate the necessary hydrogen amount and power consumption of $\mathrm{H}_{2}$ blending into NG for the needs of the Latvian economy sectors. We chose as an example the total consumption of natural gas in Latvia in 2018 by sector [19], not taking into account the transferred amount across the borders: industry and construction - 139; households - 146; services (commercial and public sector) - 129; agriculture, forestry and fisheries -8 ; all together 422 million $\mathrm{m}^{3}$. Assuming low losses and more than $55 \%$ efficiency of alkaline electrolyzer, results are depicted in Fig. 3. In order to reach the desired blends, substantial amount of power has to be produced that, at this moment, exceeds production availability. Wind power production increases every year, reaching 24 GWh in January 2020 alone. Similar trend can be seen for solar power [15]. However, local power production in Latvia is not zero-sum, as it is not simple to input produced excess power into the national grid. On the other hand, excess power could be converted into hydrogen and injected into NG or stored for later use as backup in combination with fuel cell in some centralised underground storage facilities, which are identified in Zemgale and Kurzeme regions, but that is not within the scope of this paper.

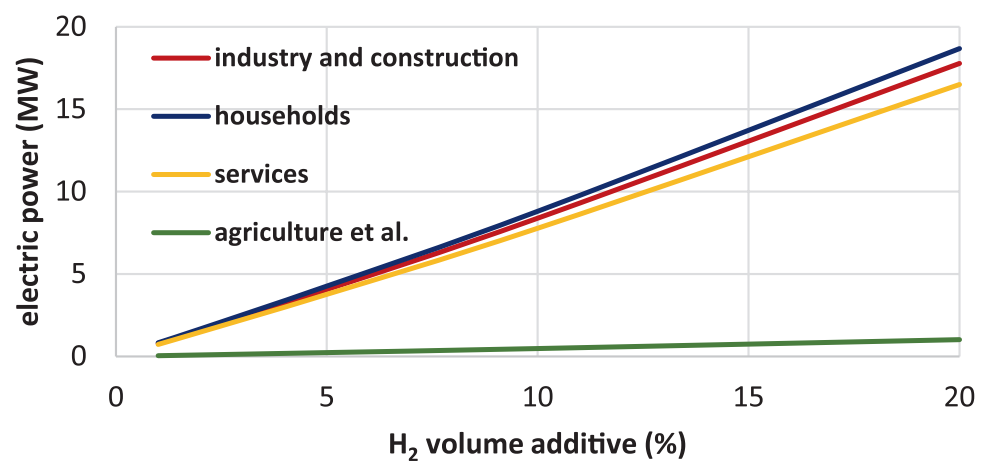

Fig. 3. Hydrogen production power requirements for the Latvian economy sectors considering various possible blends from $1 \%$ to $20 \%$ by volume.

\subsection{Evaluations of $\mathrm{H}_{2} / \mathrm{NG}$ Blends and Saved $\mathrm{CO}_{2}$ Emission Amounts}

To define the acceptable hydrogen level for each network subzone, it is therefore necessary to establish which of its equipment is most sensitive to hydrogen. Both the tests carried out in European projects (Naturalhy, Ameland) and those in GRHYD show that residential customers' equipment can operate at a hydrogen level of $20 \%$ (or even $30 \%$ ), with no loss of production performance and with a reduction in nitrogen oxides and carbon monoxide emissions [12]. As the lower heating value (LHV) of hydrogen is $10.8 \mathrm{MJ} / \mathrm{Sm}^{3}$ that is less than that of natural gas $\left(35.8 \mathrm{MJ} / \mathrm{Sm}^{3}\right)$, by adding an amount of hydrogen to the NG the overall flow rate must be slightly increased to keep an initial combustion heat value. It can be easily calculated by summing up the volume fractions. To convert the saved flow of $\mathrm{NG}$ to the $\mathrm{CO}_{2}$ emission amount, we base on the widely used stoichiometric considerations that $1 \mathrm{Nm}^{3}$ of $\mathrm{NG}$ results in $1.92 \mathrm{~kg}$ of $\mathrm{CO}_{2}$ at complete combustion (Fig. 4). 


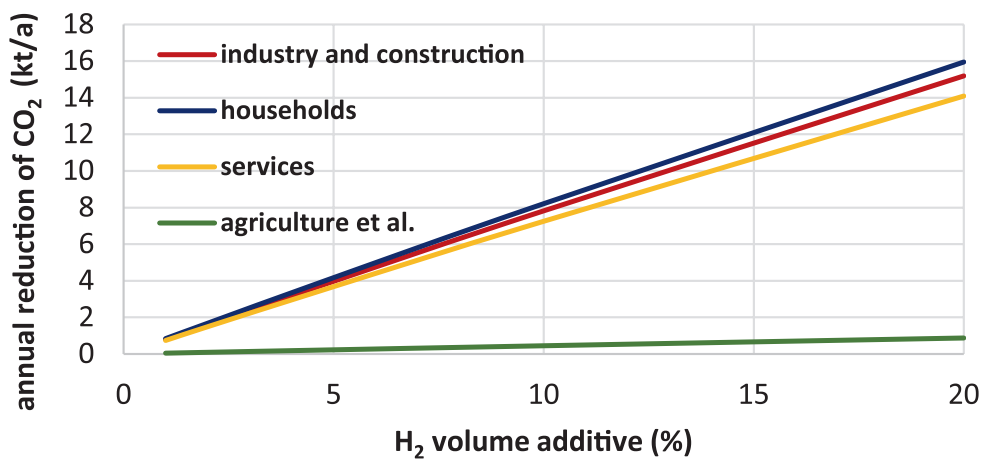

Fig. 4. Annual reduction of carbon dioxide emissions from the Latvian economy sectors using NG in dependence of blending hydrogen amount.

It is a significant amount of $\mathrm{CO}_{2}$ reduction that can be reached by increasing the potential hydrogen mix in the natural gas system (see total final consumption of natural gas and final consumption by sector in Latvia, million $\mathrm{m}^{3}$, and savings of $\mathrm{CO}_{2}$ emissions for end-users - Fig. 4). Thus, to use the HCNG in the distribution system the equipment of end users must be hydrogen proof if concentration exceeds $20 \mathrm{vol} \%$ [4], [7].

As one of the options is to only use NG system for hydrogen transportation. A set pipeline system should be used while it is possible to separate the hydrogen from the NG system. This means that separation equipment must be installed prior distribution system network to separate the hydrogen from the NG mix. Solutions currently exist but must mature before they become available at reasonable costs. Separation could also eventually be used to recover pure hydrogen to supply dedicated uses [12]. This means that separated hydrogen could be used for transport applications if it is purified to the $99.999 \%$. The possibility for hydrogen transportation would allow a potential hydrogen refueling station infrastructure holder to deploy hydrogen refueling stations close to the existing transmission natural gas network and install separation and purifying equipment. Note that the hydrogen transportation using the NG system does not decarbonise the system itself. To decarbonise the natural gas system, the HCNG must be used in end-user applications.

\subsection{Operational Aspects and the Allowed Hydrogen Content}

One of the aspects that must be considered is the overall gas quality characteristics. The gas quality of the NG distribution system is set in legislative acts. The Regulation Regarding the Trade and Use of Natural Gas includes the overall natural gas quality characteristics and states that the hydrogen allowance in the natural gas mix is $\leq 0.1 \mathrm{~mol} \%$ [21]. The set amount of hydrogen allowance in the NG mix in the distribution system allows for the end-users to be sure that the installed technological units such as turbines, heating boilers etc. do not have to be "hydrogen-capable" as the overall amount of hydrogen in the mix will not affect the equipment operation.

The usage of NG tubes for hydrogen transportation is already under evaluation in various parts of Europe. In the case of Latvia, the Cabinet regulation "Requirements for the Injection and Transportation of Biomethane and Gaseous Liquefied Nat- 
ural Gas in the Natural Gas Transmission and Distribution System" sets the overall allowed gas mixture that can be injected in the natural gas system. Note that the allowed hydrogen content in the mix is the previously mentioned $\leq 0.1 \mathrm{~mol} \%$. To use hydrogen for natural gas grid decarbonisation, the amendment of the previously mentioned legislative act should be made.

The regulation "Requirements for the Injection and Transportation of Biomethane and Gaseous Liquefied Natural Gas in the Natural Gas Transmission and Distribution System" sets definitions of "base gas", "substitution gas" and "additive gas" [22]:

- "Base gas" is natural gas obtained from natural deposits to be transported in the natural gas transmission and distribution system;

- "Substitution gas" is biomethane and liquefied natural gas converted to a gaseous state which, at the same pressure, temperature and unchanged regulation of the gas appliance, has identical combustion characteristics to the base gas. Substitution gas may be used instead of base gas;

- "Additive gas" is bio-methane the quality characteristics of which differ from the basic gas. When mixing with base gas the required quality can be obtained or mixing with conditioning gas it is possible to get substitution gas.

Firstly, in order to allow the use of hydrogen in the NG networks in Latvia, the determined thresholds of hydrogen should be increased from 0.1 to $20 \mathrm{vol} \%$ as it is evaluated in this study. The current allowance does not open the path for NG network decarbonisation. Currently, hydrogen is not set under one of the previously mentioned definitions.

Amendment wise, hydrogen cannot be included in the "substitution gas" as the hydrogen combustion characteristics differ from the base gas. The option is that hydrogen should be included as "additive gas" with reference that "additive gas is biomethane or hydrogen (...)". The amendment is necessary as also with HCNG blend it is possible to reach the quality characteristics.

Thus, in order to make the amendments, different operational aspects must be considered to increase the hydrogen mix in the NG system. This includes the risk of leaks, integrity risks (a problem similar to that of pipes), and malfunctions.

\section{CONCLUSIONS}

Our evaluation of the current energy grid has put forward the following aspects that need to be addressed. Firstly, introduction of hydrogen into natural gas consumption via blending can lower carbon dioxide emissions. By increasing the hydrogen fraction from $0.1 \%$ to $20 \%$ in the natural gas and hydrogen blend, the carbon dioxide emissions decrease accordingly due to the reduced natural gas fraction from $100 \%$ to $80 \%$. In the considered household sector, the total annual reduction reaches 52 kilotonnes of $\mathrm{CO}_{2}$. Secondly, Latvia has an extensive central NG transportation grid connected to neighbouring countries, enabling additional $\mathrm{H}_{2}$ transportation within Latvia and potentially exporting it. But there are legislative and technical obstacles to the introduction of $\mathrm{H}_{2}$ at this moment.

The first obstacle - to enable the hydrogen allowance in the NG networks in Latvia, the allowed threshold of hydrogen should be increased from 0.1 to $20 \mathrm{vol} \%$. It would allow using the gas transmission network for $\mathrm{H}_{2}$ transportation. As the experience of some European countries shows, even with- 
out separating hydrogen from natural gas, there would be no impact on end-users and gas infrastructure.

The second obstacle is the inappropriate section of the current NG network for hydrogen transportation (oldest pipes from 1967). These sections must be updated.

The ability of hydrogen injection into NG network as a central storage facility should be further investigated. As the local green hydrogen production stakeholders are slowly gaining momentum, also the natural caves should be evaluated as a potential hydrogen storage facility in Latvia.

About 5090 tonnes of hydrogen annually can be produced from surplus elec- tricity, about 280 GWh annually from the spring floods in the largest river of Latvia, the Daugava, on which three of Latvia's largest hydroelectric power plants are located.

Combination of $\mathrm{H}_{2}$ production with excess power, introduction in NG network for transportation would allow a potential hydrogen refuelling station infrastructure holder to deploy hydrogen refuelling stations close to the existing transmission natural gas network and install hydrogen separation and purifying equipment, and therefore the produced hydrogen could enable to decarbonise the transport sector.

\section{ACKNOWLEDGEMENTS}

The research has been funded by the Ministry of Economics of the Republic of Latvia, project "Trends, Challenges and
Solutions of Latvian Gas Infrastructure Development (LAGAS)", project No. VPPEM-INFRA-2018/1-0003.

\section{REFERENCES}

1. European Commission. (2020). Powering $a$ Climate-Neutral Economy: An EU Strategy for Energy System Integration. Brussels, 8.7.2020, COM (2020) 299 final. Available at https://ec.europa.eu/energy/sites/ener/files/ energy_system_integration_strategy_pdf

2. European Commission. (2019). Hydrogen. Available at https:/ec.europa.eu/energy/ topics/energy-system-integration/hydrogen en

3. BloombergNEF. (2020). Hydrogen Economy Outlook. Available at https://data. bloomberglp.com/professional/sites/24/ BNEF-Hydrogen-Economy-Outlook-KeyMessages-30-Mar-2020.pdf

4. European Hydrogen Backbone. (2020). European Hydrogen Backbone - Gas for Climate 2050. Available at https:// gasforclimate2050.eu/sdm_downloads/ european-hydrogen-backbone/

5. GRTgaz. (2019). Technical and Economic
Conditions for Injecting Hydrogen into Natural Gas Networks. Final report, France. Available at https://www.grtgaz.com/ fileadmin/plaquettes/en/2019/Technicaleconomic-conditions-for-injecting-hydrogeninto-natural-gas-networks-report2019.pdf

6. Pellegrini, M., Guzzini, A., \& Saccani, C. (2020). A Preliminary Assessment of the Potential of Low Percentage Green Hydrogen Blending in the Italian Natural Gas Network. Energies, 13, 5570. doi:10.3390/en13215570

7. HyDeploy. (2020). Is a Pioneering Hydrogen Energy Project Designed to Help Reduce UK CO2 Emissions. Available at https://hydeploy.co.uk/

8. Ministry for Environmental Protection and Regional Development. (2019). Latvia's Strategy for Climate Neutrality by 2050. Available at https://unfccc.int/sites/default/ files/resource/LTS1_Latvia.pdf 
9. Conexus Baltic Grid. (2020). Is a Unified Natural Gas Transmission and Storage Operator in Latvia. Available at https:// www.conexus.lv/en

10. Zemite, L., Kutjuns, A., Bode, I., Kunickis, M., \& Zeltins, N. (2018). Risk Treatment and System Recovery Analysis of Gas System of Gas and Electricity Network of Latvia. Latvian Journal of Physics and Technical Sciences, 55 (5), 3-14. doi: 10.2478/lpts-2018-0031

11. Zemite, L., Bode, I., Zeltins, N., Kutjuns, A., \& Zbanovs, A. (2018). Analysis of the power system damage hazard from the point of view of the gas supply system. In 2018 IEEE International Conference on Environment and Electrical Engineering and 2018 IEEE Industrial and Commercial Power Systems Europe, EEEIC/I and CPS Europe 2018, (art. no. 8494380), 12-15 June 2018, Palermo, Italy. doi: 10.1109/ EEEIC.2018.8494380

12. Koposovs, A., Bode, I., Zemite, L., Selickis, A., \& Jasevics, (2019). A. Optimization of the Selection Method for Reconstruction of Outworn Gas Distribution Pipeline. Latvian Journal of Physics and Technical Sciences, 56 (5), 33-44, doi: 10.2478/lpts-2019-0029

13. Storeenergy. (n.d.). Energy Storage Report. Available at https://www.storengy.com/ en/our-jobs/renewable-gases/our-latestprojects

14. Savickis, J., Zemite, L., Zeltins, N., Selickis, A., \& Ansone, A. (2020). The Biomethane Injection into the Natural Gas Networks: The EU's Gas Synergy Path. Latvian Journal of Physics and Technical Sciences, 57 (4), 34-50. doi: 10.2478/lpts-2020-0020

15. AST. (2020). Latvian Electricity Market Overview. Available at https:/www.ast.lv/en/ electricity-market-review?year $=2018$ \& month $=13$
16. Telicko, J., Heincis, D., \& Jakovics, A. (2020). A Study of Solar Panel Efficiency in Latvian Climate Conditions. E3S Web of Conferences, 172, 1-4. https://doi. org/10.1051/e3sconf/202017216007

17. Lauka, D., Pakere, I., \& Blumberga, D. (2018). First Solar Power Plant in Latvia. Analysis of Operational Data. Energy Procedia, 147, 162-165. https://doi. org/10.1016/j.egypro.2018.07.049

18. Soloha, R., Pakere, I., \& Blumberga, D. (2017). Solar Energy Use in District Heating Systems. A Case Study in Latvia. Energy, 137, 586-594. https://doi.org/10.1016/j. energy.2017.04.151

19. CSP. (2018). Latvijas energobilance 2017. gadā. Availabe at https://www.csb.gov. lv/lv/statistika/statistikas-temas/videenergetika/energetika/meklet-tema/332energobilance-2017-gada

20. Aniskevich, S., Bezrukovs, V., Zandovskis, U., \& Bezrukovs, D. (2017). Modelling the Spatial Distribution of Wind Energy Resources in Latvia. Latvian Journal of Physics and Technical Sciences, 54 (6), 10 20. https://doi.org/10.1515/lpts-2017-0037

21. Cabinet of Ministers. (2017). Regulation No. 78. Regulations Regarding the Trade and Use of Natural Gas. Latvijas Vēstnesis. Available at https://likumi.lv/ta/id/289031

22. Ministru kabinets. (2016). Ministru kabineta 2016. gada 4. oktobra noteikumi Nr. 650 Prasības biometāna un gāzveida stāvoklī pārvērstas sašķidrinātās dabasgāzes ievadīšanai un transportēšanai dabasgāzes pārvades un sadales sistēmā. Latvijas Vēstnesis. Available at https://likumi.lv/ta/ $\mathrm{id} / 285189$ 